\title{
Energy Audit of MC-1
}

\section{Introduction}

The goal of the Muon g-2 project is to measure the muon magnetic anomalous moment to a precision of $140 \mathrm{ppb}$. This is an unprecedented endeavor that will allow for the comparison of the standard model's prediction and experimental value of the muon magnetic anomaly. If the difference is statistically significant this could mean there is physics beyond the standard model.

The g-2 project conducts the experiment in the MC-1 building located just south of Wilson Hall. The building is relatively new having completed construction in 2014 .

An energy audit is an assessment of a building's energy use and determines energy efficiency measures that can be implemented to make a building more efficient. While other buildings at Fermilab have undergone an energy audit, this will be the first one done for MC-1.

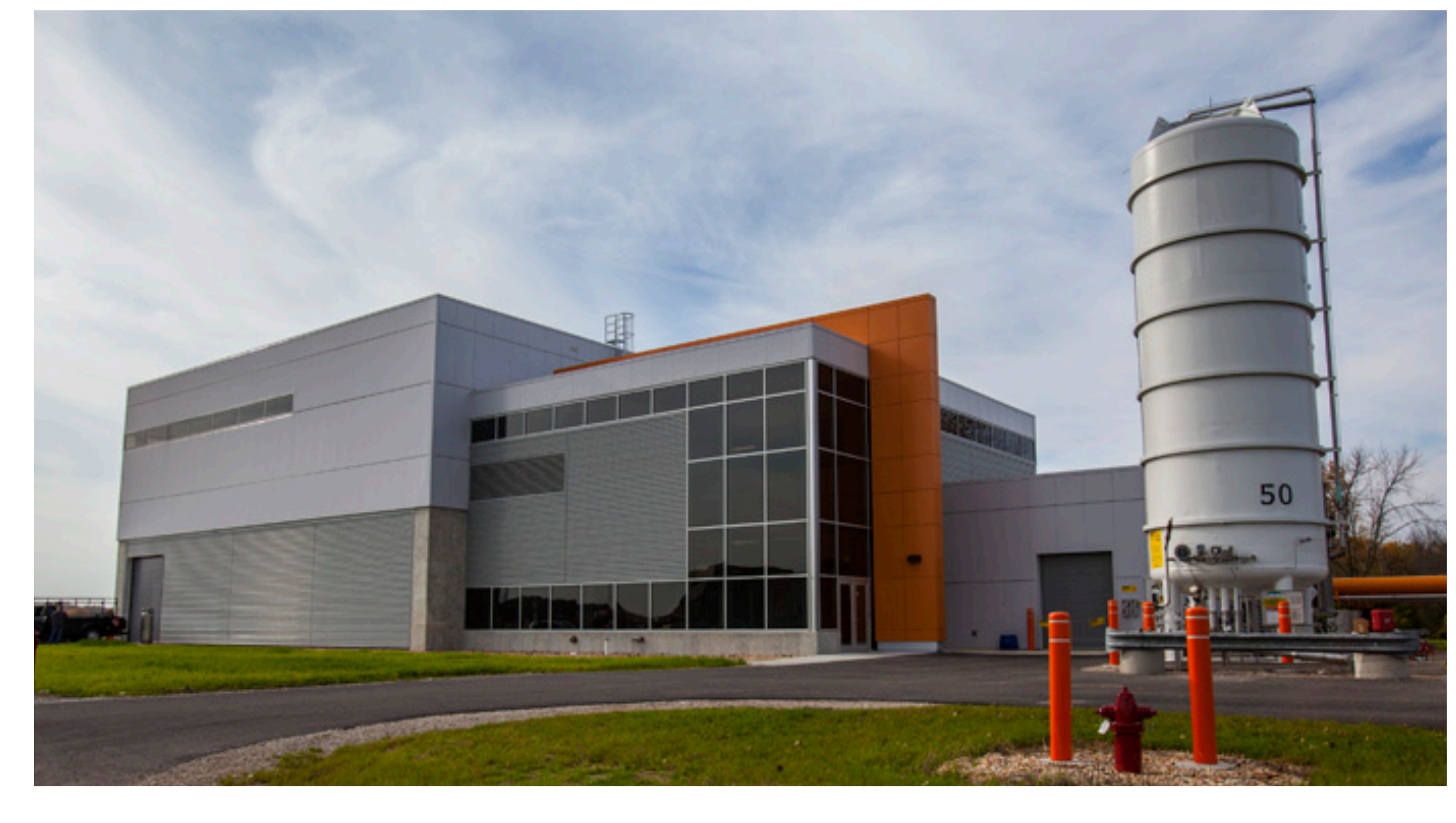

Exterior shot of MC-1

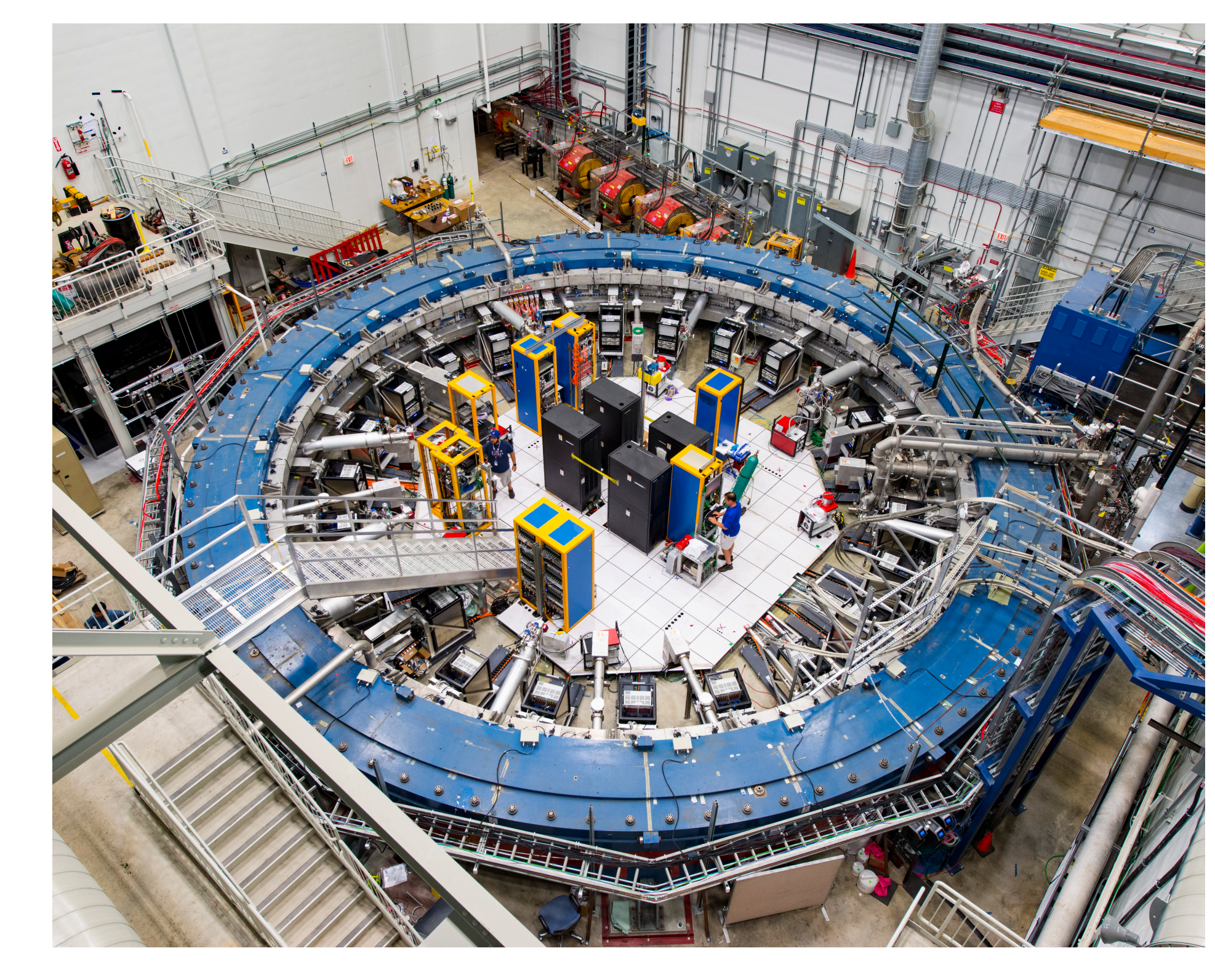

Storage ring for the g-2 experiment

\section{Methods}

MC-1's energy consumption and costs were first determined and compared to local weather data. Electricity consumption data for 2019 was accessed using Power Monitoring Expert (PME). Natural gas usage data for 2019 was manually read from gasmeters located on-site. Outside temperature data was obtained using the National Oceanic and Atmospheric Administration (NOAA) online climate data tool. Costs estimates were made using an overall average sitewide cost of $\$ 0.0467 / \mathrm{kWh}$ and \$0.32/therms.

The lighting subsystem at MC-1 was analyzed further to identify how much electricity the system consumes and to identify any energy efficiency improvement measures.

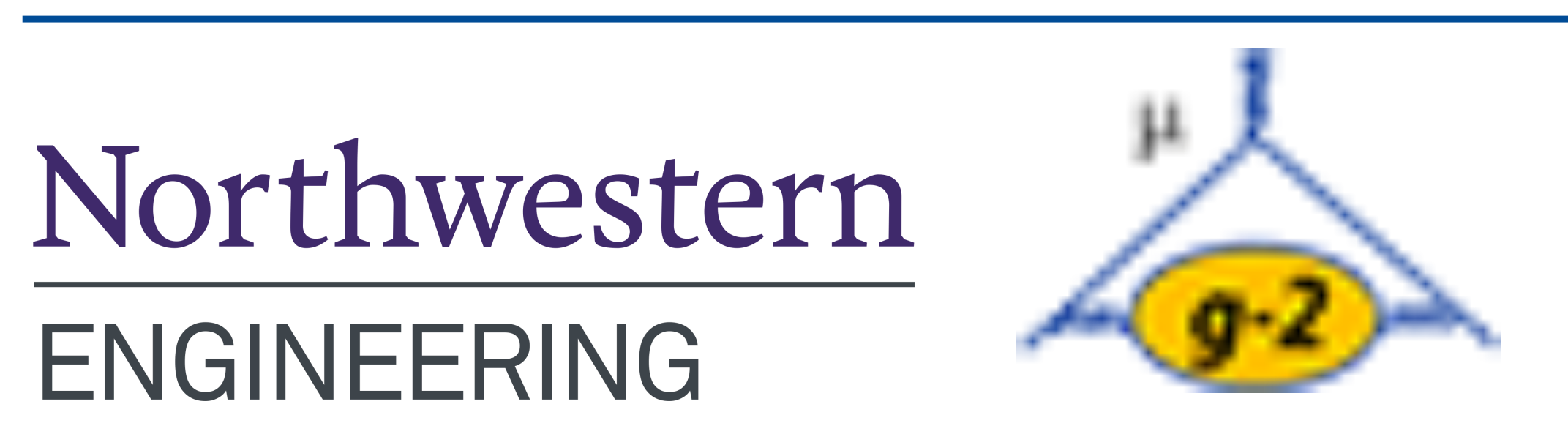

\section{Results}

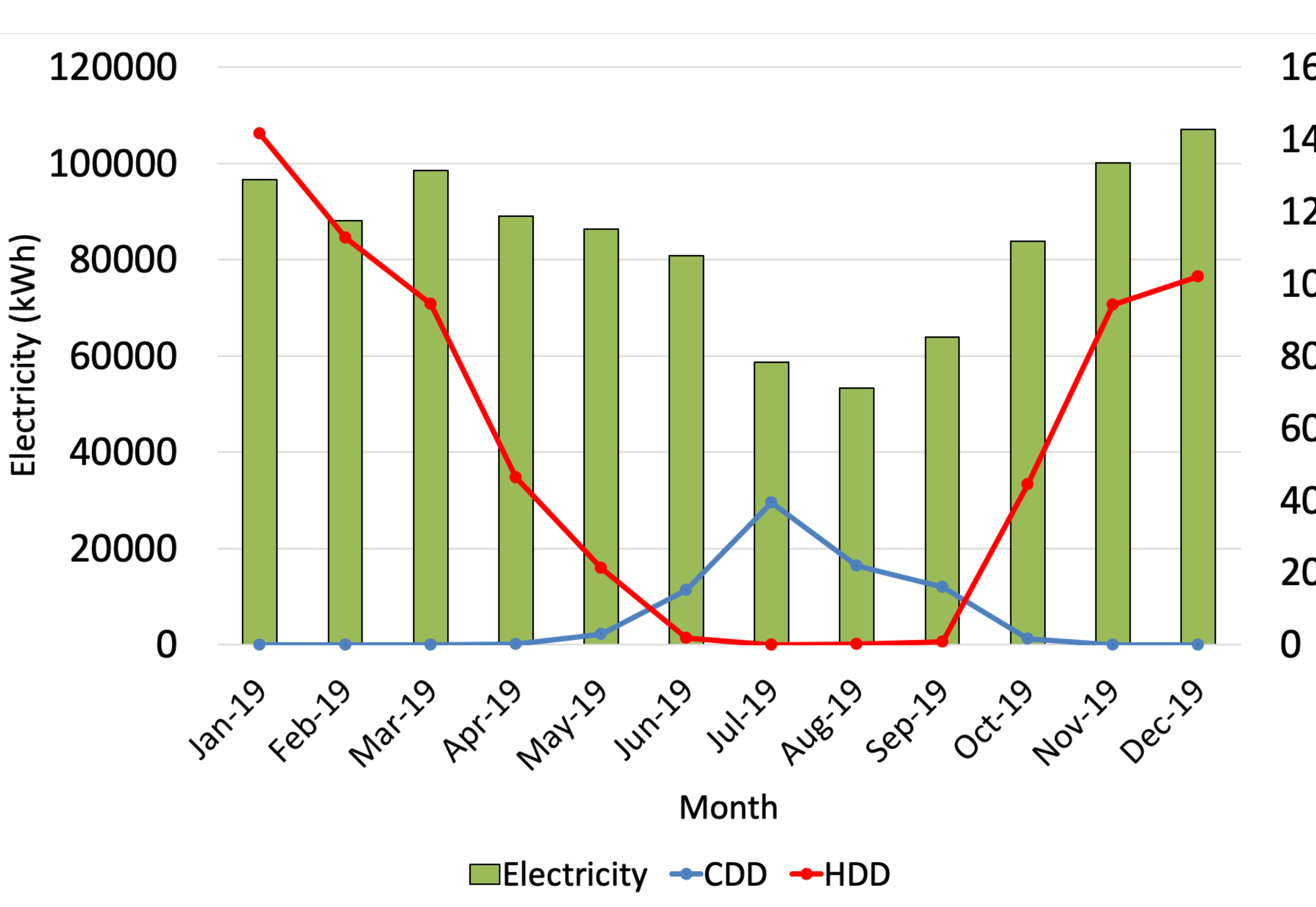

$1600 \mathrm{MC}-1$ consumed $1,006,158 \mathrm{kWh}$ of 1400 electricity in 2019 and 145 therms 1200 of natural gas in 2019. The total 1000 energy costs were $\$ 47,034$. The 800 electricity and natural gas 600 consumption per month as well as 400 monthly cooling degree days (CDD) 200 and heating degree days (HDD) is shown in the figures on the left. A degree day compares the outside temperature to the standard indoor temperature of $65^{\circ} \mathrm{F}$. Electricity

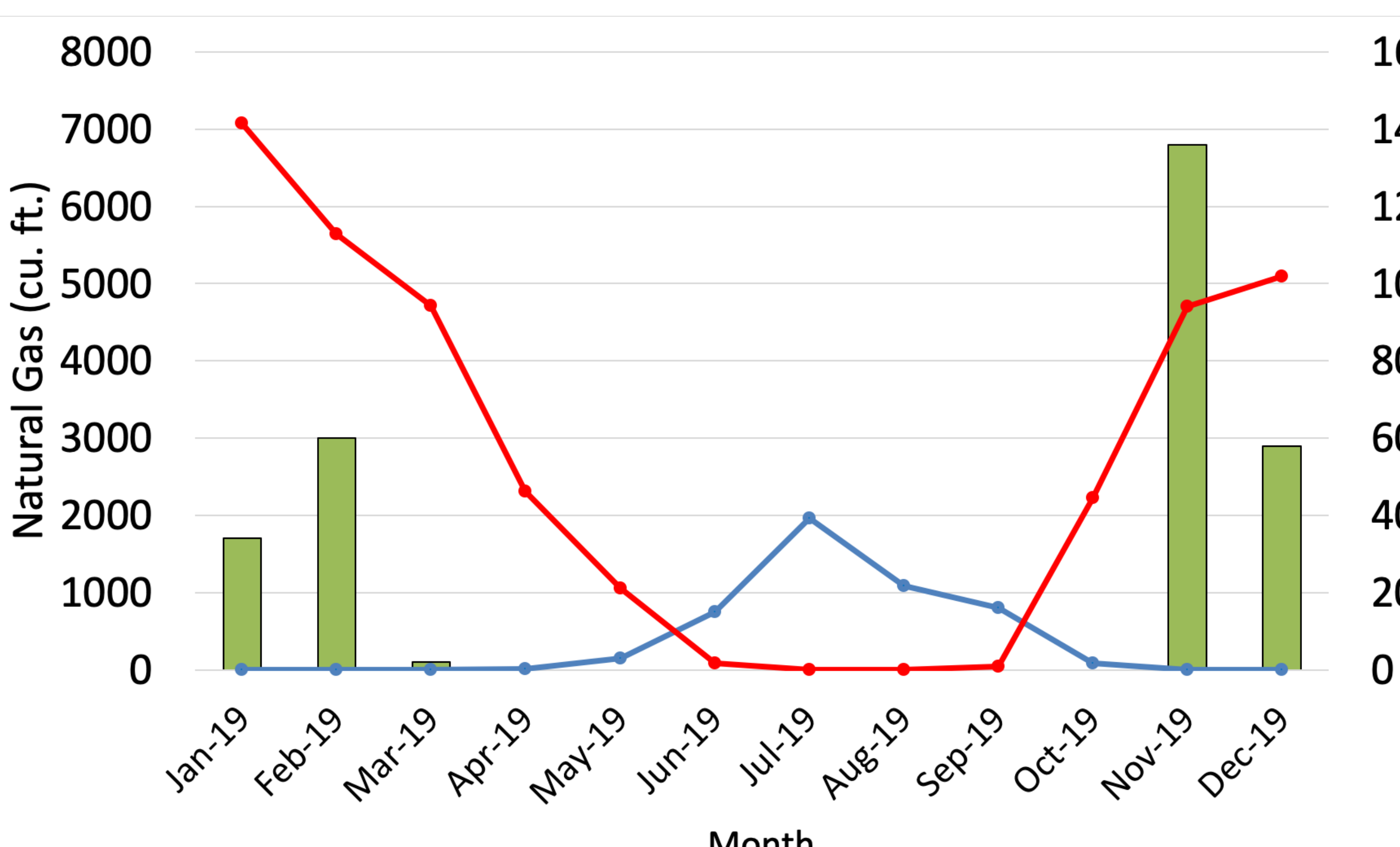
consumption declines in the 1400 summer months due to the summer 1200 shutdown that occurs where the 1000 experiment is not taking data. 800 During the winter months there is a 600 correlation seen between HDD and 400 natural gas use when heating of the 200 building is necessary.

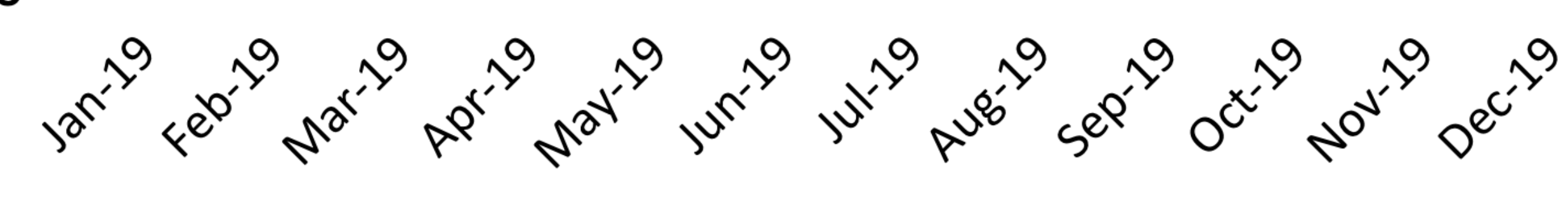$$
\text { Month }
$$

Natural Gas $\rightarrow$ CDD $\rightarrow$ HDD

Electricity and natural gas consumption vs $\mathrm{CDD}$ and HDD

\section{Conclusions}

The lighting subsystem uses a combination of fluorescent, metal halide, and LED lamps. The LED lamp is the most energy efficient while the metal halides were the least. The total annual energy consumption from lighting was 7,635 kWh. Replacing all lamps with LEDs would reduce MC-1's energy consumption from lighting the building by $62 \%$ and would save $\$ 230 / y r$ in electricity costs.

This is just one energy cost reduction measure (ECRM) that MC-1 could implement. Future in-depth analysis into the power consumption of other subsystems at this site would provide more energy savings and reduce the buildings environmental footprint. 